\title{
Management of Depression and Uses of Natural Medicine
}

\section{Saif UI Islam}

Rite Aid Corporation, 2169 Peakview Ave, Sacramento, CA, USA

*Corresponding author: Saif ul Islam, Rite Aid Corporation, 2169 Peakview Ave, Sacramento, CA-95835, USA, Tel: (360)348-8475; E-mail: saif_1104@yahoo.com

Rec date: September 11, 2015 Acc date: September 24, 2015 Pub date: September 30, 2015

Copyright: (C) 2015 Islam SU. This is an open-access article distributed under the terms of the Creative Commons Attribution License, which permits unrestricted use, distribution, and reproduction in any medium, provided the original author and source are credited.

\begin{abstract}
Depression is a one of the leading cause of disability. It is estimated that approximately $17 \%$ of the world's population and $18 \%$ of the US population experience major depression in their lifetime. Women are almost twice as likely to experience major depression as men. The suicidal rate is four times higher among those with depression than those without depression. Use of herbal medicine is an important part of the evidence-based treatment of depression. Patients are more inclined to use herbal products than ever before and physicians are often asked about herbal medicine. Most of our curriculum in medical school does not or only briefly touch on this topic. Several clinical studies have shown that St. John's wort and SAMe may be an option in the treatment of mild to moderate depression or where patient prefer herbal over conventional treatment.
\end{abstract}

Keywords: Depression; St. John's wort; SAMe

\section{Introduction}

Depression is a debilitating mental problem that could affect any one. Women are more prone to a depression than men. Unmarried, middle aged, being disabled or unemployed, and family history of depression are some of the few factors that can make a person more susceptible to a depression. Use of herbal medicine is so common in everyday life that we cannot deny that it is important. Store shelves are full of various products that are used in depression. Given that not all brands are equal. There is a different in quality, purity and content of each product. Herbal medicines are considered a health food and are therefore not regulated by the Food and Drug Administration (FDA) as a drug. While supporting clinical data regarding herbal medicines in depression are ambiguous, primary care providers may often be asked about the safety, effectiveness and side effects of these products [1].

The purpose of this article is to review conventional treatment and provide information about the safety, product selection, drug interaction and the side effects of herbal medicines that have strong evidence in the treatment of depression. Herbal medicines with weak or lack of evidence are not discussed.

\section{Pathophysiology of Depression}

The exact etiology of depression is not known. While, there are several hypotheses, there is no unified theory that can explain the pathophysiology of all types of depression all the time across the course of the illness.

The most common theory is that depression is caused by an imbalance of neurotransmitters, such as norepinephrine, serotonin and dopamine in the brain. Then we have a theory of genetic vulnerability from familial, adoption and twin studies. However, no specific gene or interaction of genes has been identified that could be blamed for depression. Some additional important hypotheses of depression is, monoamines deficiency, altered HPA axis activity, dysregulation of glutamate and decrease activity of gamma-aminobutyric acid (GABA). In short, depression is a multifaceted problem that involves, but is not limited to genetic, social, familial, economic and environmental factors, and it cannot be explained with a single hypothesis or theory.

\section{Conventional Treatment}

Mainstay in the treatment of depression includes psychotherapy, pharmacotherapy and electroconvulsive therapy. No treatment is $100 \%$ effective alone. Combination therapy involving psychotherapy and pharmacotherapy may yield better outcome.

\section{Pharmacotherapy}

Drug therapy in the management of depression is classified into the following categories.

\section{Serotonin Uptake Inhibitor (SSRI)}

SSRI works by inhibiting the reuptake of serotonin at presynaptic level. Comparatively new product, Vilazodone work like SSRI and also is a partial agonist of the 5-HT1A receptor. Another new product, Vortioxetine has action like SSRI plus also bind to 5-HT3 and 5-HT1A receptor. In clinical trials all SSRIs showed similar efficacy with difference in dosing, side effects, and drug interactions (Table 1).

\begin{tabular}{|l|l|}
\hline Agent & Normal daily dosage \\
\hline Citalopram & $20-40 \mathrm{mg}$ per day \\
\hline Escitalopram & $10-20 \mathrm{mg}$ per day \\
\hline Fluoxetine & $20-60 \mathrm{mg}$ per day \\
\hline Sertraline & $25-200 \mathrm{mg}$ per day \\
\hline Paroxetine & $20-40 \mathrm{mg}$ per day \\
\hline Vilazodone & $20-40 \mathrm{mg}$ per day \\
\hline Vortioxetone & $20 \mathrm{mg}$ per day \\
\hline
\end{tabular}

Table 1: Different SSRI drugs and their dosages. Source: Merck Manual, $19^{\text {th }}$ edition, 2011 [2]. 
Page 2 of 4

\section{Serotonin-Norepinephrine Reuptake Inhibitor (SNRI)}

These agents inhibit serotonin, norepinephrine and dopamine reuptake. They have similar efficacy as SSRI and are considered firstline agents as well SSRI. Some agents of this class such as duloxetine are also used for fibromyalgia (Table 2).

\begin{tabular}{|l|l|}
\hline Agent & Normal Daily Dosage \\
\hline Desvenlafaxine & $50 \mathrm{mg}$ \\
\hline Duloxetine & $30-60 \mathrm{mg}$ \\
\hline Levomilnacipran & $40-120 \mathrm{mg}$ \\
\hline Venlafaxine & $25-150 \mathrm{mg}$ \\
\hline
\end{tabular}

Table 2: Different SNRI drugs and their dosages. Source: Merck Manual, $19^{\text {th }}$ edition, 2011 [2].

\section{Atypical Antipsychotics}

These agents are used as an adjunctive therapy. The FDA has approved Aripiprazole and quetiapine as anti-depressant add-ons. Dosage is usually the same as in schizophrenia but some studies have shown that lower dosage might also be affective and have fewer side effects [3] (Table 3).

\begin{tabular}{|l|l|}
\hline Agent & Normal Daily Dosage \\
\hline Arispiprazole & $10-30 \mathrm{mg}$ \\
\hline Olanzapine & $10-20 \mathrm{mg}$ \\
\hline Quetapine & $150-375 \mathrm{mg}$ \\
\hline Risperidone & $4-10 \mathrm{mg}$ \\
\hline
\end{tabular}

Table 3: Different atypical antipsychotics drugs and their dosages. Source: Merck Manual, $19^{\text {th }}$ edition, 2011 [2].

\section{Norepinepherine-Dopamine-Reuptake Inhibitor}

Bupropion is the only agent in this class. It is also effective as smoking cessation therapy. Bupropion may cause hypertension and seizure in some patients (Table 4).

\begin{tabular}{|l|l|}
\hline Agent & Normal Daily Dosage \\
\hline Bupropion & $150-450 \mathrm{mg}$ \\
\hline
\end{tabular}

Table 4: Norepinepherine-dopamine-reuptake inhibitor drug and it's dosage. Source: Merck Manual, $19^{\text {th }}$ edition, 2011 [2].

\section{Noradrenergic Antagonist-Serotonin Modulators}

These agents block 5-HT and alpha-2 adrenergic receptor. They are highly sedative, particularly trazadone, which may also cause priapism and orthostatic hypotension, while mirtazapine cause weight gain (Table 5).

\begin{tabular}{|l|l|}
\hline Agent & Normal Daily Dosage \\
\hline Nefazodone & $300-500 \mathrm{mg}$ \\
\hline Mirtazipine & $15-45 \mathrm{mg}$ \\
\hline
\end{tabular}

Trazadone

$150-300 \mathrm{mg}$

Table 5: Noradrenergic Antagonist-Serotonin Modulators and their dosages. Source: Merck Manual, $19^{\text {th }}$ edition, 2011 [2].

\section{Tricyclic Antidepresent (TCA)}

These agents are no longer use as a first line therapy in the management of depression due to their side effects, non-specificity and drug interactions. Some studies have shown that TCAs may work better in severely depressed hospitalized patients (Table 6).

\begin{tabular}{|l|l|}
\hline Agent & Normal Daily Dosage \\
\hline Amitriptyline & $100-300 \mathrm{mg}$ \\
\hline Desipramine & $100-300 \mathrm{mg}$ \\
\hline Doxepine & $100-300 \mathrm{mg}$ \\
\hline Imipramine & $100-300 \mathrm{mg}$ \\
\hline Nortriptaline & $50-200 \mathrm{mg}$ \\
\hline
\end{tabular}

Table 6: Tricyclic Antidepresent (TCA) drugs and their dosages. Source: Merck Manual, $19^{\text {th }}$ edition, 2011 [2].

\section{Monoamine Oxidase Inhibitors}

These agents are generally used to treat refractory or atypical depression when other options fail. They inhibit both MAO-A and MAO-B. Major problem with these agents is their side effects, drug and food interaction (Table 7).

\begin{tabular}{|l|l|}
\hline Agent & Normal Daily Dosage \\
\hline Isocarboxazide & $30-60 \mathrm{mg}$ \\
\hline Phenelzine & $45-90 \mathrm{mg}$ \\
\hline Tranylcypromine & $30-60 \mathrm{mg}$ \\
\hline
\end{tabular}

Table 7: Monoamine Oxidase Inhibitors and their dosages. Source: Merck Manual, $19^{\text {th }}$ edition, 2011 [2].

\section{Natural Medicine}

There are several natural medicines available over the counters that are used to treat depression. Are they truly effective? In most cases, not enough data are available to justify their use in depression. However, clinical studies have shown that ST. John's wort and SAMe might have some value in the treatment of depression.

\section{ST. John's Wort}

Botanical name is Hypericum perforatum. It is a perennial plant indigenous to Europe and other part of world. The main constituents that are considered to have anti-depressant effects are hypercin and hyperforin. St. John's wort works by inhibiting the reuptake of serotonin, norepinephrine, and dopamine and also has some effects on glutamate and gamma-aminobutyric acid (GABA) [4,5].

Published clinical trials, reviews and meta-analysis about St. John's wort are conflicting. Some studies have shown that St. John's wort is no better than placebo and some studies showed the efficacy equivalent to 
Page 3 of 4

standard antidepressant in mild to moderate depression. The reason for the contradictory results is unclear. Critics also objected about the population size and duration of treatment of these trials. Results from two large clinical trials $(\mathrm{n}=200, \mathrm{n}=340)$ conducted in outpatient psychiatric centers were published in JAMA in 2001 and 2002 [6,7]. The trials concluded that St. John's wort was not superior to a placebo in the treatment of depression.

However, the vast majority of the clinical studies have shown that St. John,s wort is effective in cases of mild to moderate depression [4,8-10]. In a meta analysis [10] and in a randomized, multicenter, double blinded, parallel group trial [11] concluded that St. john's wort was of equivalent in effectiveness to tricyclic antidepressants in treating mild to moderate depression. In other studies St. John's wort comparable to fluoxetine [11-14].

Cochran review included 29 trails $(\mathrm{n}=5489), 18$ comparisons with a placebo and 17 comparisons with standard antidepressants. The authors of the review concluded that hypericum extracts were superior to the placebo $(\mathrm{RR}=1.28,95 \%$ confidence interval, 1.10-1.49) and have similar efficacy to conventional antidepressants (RR 1.02, 95\% CI, 0.90-1.11) with fewer side effects than tricyclic antidepressant (TCA) [5].

The problem with St. John's wort is its drug interactions. St.John,s wort is a potent CYP3A4 inducer, which interacts with many drugs. Therefore, it should be avoided if the patient is on other medications.

\section{List of some drugs that interacts with St. John's wort}

- Clopidogrel

- Cyclosporine

- Digoxin

- Fexofenadine

- Imatinib

- Indinavir

- Irinotecan

- Nevirapine

- Paroxetine

- Simvastatin

- Tacrolimus

- Warfarin

Note: This is not a complete list of drugs that interacts with St. John's wort.

A meta-analysis done by Lind et al. included 37 double-blind randomized controlled trials. The authors concluded that larger placebo-controlled trials restricted to patients with major depression showed no clinically significant difference between St. John's wort and placebo. However, smaller and older trials not restricted to major depression showed clinical significant result similar to conventional antidepressant [15]. In 2001, the Canadian Psychiatric Association and The Canadian Network for Mood and Anxiety Treatments (CANMAT) published an evidence-based clinical guideline for the treatment of depression. There was level 1 evidence in support for the use of St. John's wort in mild to moderate depression and supporting evidence in the use of SAMe [16].

\section{Product Selection and Dosage}

Most of the available products are standardized to $0.3 \%$ hypericin or $3 \%$ to $5 \%$ hyperforin content and should be taken in $300 \mathrm{mg}$ three times daily for mild to moderate depression. Since St. John's wort is not controlled by FDA as a drug, there is a difference in content, quality and purity of each product. Which product is safe and have quality ingredient is the most common question asked by consumers. Natural medicine comprehensive database has developed a ranking system for herbal medicines that is called NMBER rating system (Natural Medicine Brand Evidence-based Rating). It is based on safety, quality and effectiveness. This rating system ranges from lowest 1 to highest 10 (Tables 8 and 9).

\begin{tabular}{|l|l|l|}
\hline Brand name & Manufacturer & NMBER \\
\hline Kira & Lichtwer Pharma & 10 \\
\hline Movana & Boehinger Ingelhelm & 10 \\
\hline Remotive & Zeller St. & $\begin{array}{l}\text { Nature's } \\
\text { International Bounty }\end{array}$ \\
\hline $\begin{array}{l}\text { Double Strenth } \\
\text { John's wort. }\end{array}$ & $\begin{array}{l}\text { WN Pharmaceceutical } \\
\text { Ltd }\end{array}$ & 9 \\
\hline Co Op St. John's Wort & \\
\hline
\end{tabular}

Table 8: Some of the highest quality brands are listed above. More information about this ranking system can be obtained from www.naturaldatabase.therapeauticresearch.com.

\section{S-Adenosyl-L-Methionine (SAMe)}

SAMe is an amino acid derivative that is synthesized from Lmethionine in the body. SAMe is involved in the transmethylation of several reactions in the body, including the synthesis of the neurotransmitters dopamine, norepinephrine and serotonin. How SAMe works in depression is unknown, but it is thought that SAMe increase the level of neurotransmitters in the brain by increasing synthesis and change in neuronal membrane fluidity, which might facilitate signal transduction across neural membrane $[17,18]$.

In several clinical trials, SAMe was more effective than the placebo and of equivalent efficacy to tricyclic antidepressants [19]. A clinical trial by Bell et al. concluded that SAMe was superior to imipramine in depression. However, the sample size was very small $(n=9)$ [19]. A review article by Dr. Papakosta published in the journal of clinical psychiatry in 2009, concluded that the parenteral form of SAMe was more effective than a placebo and equivalently effective to tricyclic antidepressants [20]. Some clinical research showed that SAMe might be effective as an adjunct antidepressant therapy with conventional treatment [21]. The American Psychiatric Association included SAMe as a potential alternate to standard anti-depressant in patients who like natural treatment [22]. The Canadian Network for Mood and Anxiety Treatment (CANMAT) recommend SAMe second line treatment in major depression [23-25].

Parental form of SAMe is effective in mild to moderate depression. Bioavailability of oral form is poor and need higher dose to be effective. Advantage of SAMe is it's low side effects and non-existence drug interaction. 
Citation: Islam SU (2015) Management of Depression and Uses of Natural Medicine. Gen Med (Los Angel) 3: 205. doi: $10.4172 / 2327-5146.1000205$

Page 4 of 4

\section{Product selection and dosage}

200-400 per day IM or IV, Oral dosage range from 400-1600 mg per day.

\begin{tabular}{|l|l|l|}
\hline Brand & Manufacturer & NMBER \\
\hline SAMe Complete 400 mg & Nature Made & 10 \\
\hline AOR SAMe & $\begin{array}{l}\text { Advanced } \\
\text { Orthomolecular } \\
\text { Research (AOR) }\end{array}$ & 9 \\
\hline Double Strength SAMe & CVS Pharmacy & 9 \\
\hline Finest SAMe & Walgreens Pharmacy & 9 \\
\hline Mood Plus SAMe & Nature Made & 9 \\
\hline
\end{tabular}

Table 9: Product selection and dosage of S-adenosyl-L-methionine. Note: This is not a complete list, providers and consumers can find complete list at www.naturaldatabase,therapeuticsresearch.com

\section{Other Herbal Medicines}

Several other herbal medicines that claim to be effective in depression are available on the market. However, there is not enough data available to substantiate these claims. These herbal medicines include: EPA, 5-HTP, Acetyl-L-carnitine, Fish oil, Ginko, DHEA and more.

\section{Summary}

Depression is a multifaceted problem that cannot be explained by a single theory. Treatments should be individualized. While conventional therapy is a main stay in the treatment of depression, herbal medicine especially St. john's wart and SAMe may have a place in mild to moderate depression or as an add-on therapy. It may also be an option if patient prefer natural medication.

\section{References}

1. el-Mallakh RS, Wright JC, Breen KJ, Lippmann SB (1996) Clues to depression in primary care practice. Postgrad Med 100: 85-88: 93-6.

2. Merck Manual (2011) 19.

3. Berman R, Marcus R, Swanink R (2007) The efficacy and safety of aripiprazole as adjunctive therapy in major depressive disorder: a multicenter, randomized,double-blinded, placebo-controlled study. J Clin Psychiatry 68: 843-853.

4. Singer A, Wonnemann M, Müller WE (1999) Hyperforin, a major antidepressant constituent of St. John's Wort, inhibits serotonin uptake by elevating free intracellular $\mathrm{Na}+1$. J Pharmacol Exp Ther 290: 1363-1368.

5. Muller WE, Singer A, Wonnermann M (1998) Hyperforin represents the neurotransmitter reuptake inhibiting constituent of hypericum extract. Pharmacopsychiatry 31: 16-21.

6. Volz HP (1997) Controlled clinical trials of hypericum extracts in depressed patients--an overview. Pharmacopsychiatry 30 Suppl 2: 72-76.

7. Linde K, Berner M, Kriston L (2008) St Johns's wort for major depression. Cochrane Database of Systemetic Reviews. 4: CD000448.
8. Shelton RC, Keller MB, Gelenberg A, Dunner DL, Hirschfeld R, et al. (2001) Effectiveness of St John's wort in major depression: a randomized controlled trial. JAMA 285: 1978-1986.

9. Hypericum Depression Trial Study Group (2002) Effect of Hypericum perforatum (St John's wort) in major depressive disorder: a randomized controlled trial. JAMA 287: 1807-1814.

10. Witte B, Harrer G, Kaptan T, Podzuweit H, Schmidt U (1995) [Treatment of depressive symptoms with a high concentration hypericum preparation. A multicenter placebo-controlled double-blind study]. Fortschr Med 113: 404-408.

11. Laakmann G, Jahn G, Schüle C (2002) [Hypericum perforatum extract in treatment of mild to moderate depression. Clinical and pharmacological aspects]. Nervenarzt 73: 600-612.

12. Gaster B, Holroyd J (2000) St John's wort for depression: a systematic review. Arch Intern Med 160: 152-156.

13. Kim HL, Streltzer J, Goebert D (1999) St. John's wort for depression: a meta-analysis of well-defined clinical trials. J Nerv Ment Dis 187: 532-538.

14. Philipp M, Kohnen R, Hiller KO (1999) Hypericum extract versus imipramine or placebo in patients with moderate depression: randomised multicentre study of treatment for eight weeks. BMJ 319: 1534-1538.

15. Harrer G, Schmidt U, Kuhn U, Biller A (1999) Comparison of equivalence between the St. John's wort extract LoHyp-57 and fluoxetine. Arzneimittelforschung 49: 289-296.

16. Schrader E (2000) Equivalence of St John's wort extract (Ze 117) and fluoxetine: a randomized, controlled study in mild-moderate depression. Int Clin Psychopharmacol 15: 61-68.

17. Linde K, Berner M, Egger M, Mulrow C (2005) St John's wort for depression: meta-analysis of randomised controlled trials. Br J Psychiatry 186: 99-107.

18. Ravindran AV, Lam RW, Filteau MJ (2009) Canadian Network for Mood and Anxiety Treatments (CANMAT) Clinical guidelines for the management of major depressive disorder in adults. V. Complementary and alternative medicine treatments. J Affect Disord 117: 54-64.

19. Rosenbaum JF, Fava M, Falk WE, Pollack MH, Cohen LS, et al. (1990) The antidepressant potential of oral S-adenosyl-1-methionine. Acta Psychiatr Scand 81: 432-436.

20. Bottiglieri T, Hyland K, Reynolds EH (1994) The clinical potential of ademetionine (S-adenosylmethionine) in neurological disorders. Drugs 48: 137-152.

21. Spillmann M, Fava M (1996) S- adenosyl-methionine (ademethionine) in psychiatric disorders. CNS Drugs 6: 416-425.

22. Bell KM Plon L, Bunney WE Jr, Potkin SG (1988) S-adenosylmethionine treatment of depression: a controlled clinical trial. Am J Psychiatry 145: 1110-1114.

23. Papakostas GI (2009) Evidence for S-adenosyl-L-methionine (SAM-e) for the treatment of major depressive disorder. J Clin Psychiatry 70 Suppl 5: 18-22.

24. Papakostas GI, Mischoulon D, Shyu I (2010) S-adenosyl methionine (SAMe) augmentation of serotonin reuptake inhibitors for antidepressant nonresponders with major depressive disorder: a double-blind, randomized clinical trial. Am J Psychiatry 167: 942-948.

25. Work Group for Major Depression Disorder (2009). Practice Guideline for the Treatment of Patients with Major Depression Disorder. American Psychiatric Association 3. 